A PRÁtICA COMO INVESTIGAC̣ÃO I PRACTICE AS RESEARCH

\title{
Choreographic transductions across media: problems and objects in the Double Skin/Double Mind project
}

\author{
CARLOS MANUEL OLIVEIRA
}

O foco deste artigo é a individuação de conhecimento coreográfico no contexto do projecto Double Skin/Double Mind, desenvolvido pelo grupo de investigação Prática e Desenvolvimento Artístico, da Escola das Artes de Amesterdão, em torno do trabalho conjunto do coreógrafo e bailarino Emio Greco e do dramaturgista Pieter Scholten. $\mathrm{O}$ artigo expõe alguns problemas associados à concepção e ao desenho de uma série de objectos multimédia, criados com o intuito de transmitir o conhecimento coreográfico destes artistas através de estruturas análogas aos conceitos organizadores das próprias danças. Estes conceitos correspondem a princípios de movimento cuja transmissão se dá por meio de transducções, tanto entre corpos como entre diferentes média. A transducção é aqui proposta como uma operação adequada ao pensamento da transmissão coreográfica, abrangendo tanto as expressões intensivas e extensivas da dança como os processos abstractos e concretos pelos quais o conhecimento que lhe está associado emerge. Os problemas abordados referem-se sobretudo à disparidade entre a dança e a escrita coreográfica, vista da perspectiva da diferença entre multiplicidades qualitativas e multiplicidades quantitativas. O projecto de investigação Double Skin/Double Mind debruçou-se sobre este conjunto de problemas no que respeita à transmissão de conhecimento coreográfico em tempos de multimodalidade digital, não sem ter de lidar com as restrições diagramáticas e linguísticas necessárias à determinação de uma continuidade de ideias coreográficas através de corpos e média descontínuos.

DANCE / CHOREOGRAPHY / KNOWLEDGE / TRANSDUCTION / MULTIMEDIA

TRANSMITTING

When asked to deliver a workshop at the Internationale Tanzwochen Wien in 1998, choreographer and dancer Emio Greco and dramaturgist Pieter C. Scholten (EG|PC) decided to create a structure that could transmit their creative method, which they named Double Skin/Double Mind 
$(D S / D M)$. After delivering this workshop in different contexts for some years, the two artists felt "the need" to better "understand the logic of the workshop and its structure" (deLahunta, 2007a: 20). In order to do this, from 2004 to 2007 the EG|PC dance company developed the Notation Research Project (NRP), in cooperation with the research group Art Practice and Artistic Development, headed by Marijke Hoogenboom at the Amsterdam School of the Arts. ${ }^{1}$ With this project, the two artists and a multi-disciplinary team of specialists strived to find a notation system that could capture "the inner intention as well as the outer shape of gestures and [dance] phrases" (ibidem, 5). Remarkably, this research generated multiple outcomes: a documentary, a DVD-ROM, a book and an interactive installation, all published together under the title (Capturing Intention): Documentation, Analysis and Notation Research Based on the Work of Emio Greco/PC (CI). ${ }^{2}$

The workshop $D S / D M$ was intended to facilitate the transmission of a series of movement principles, from Greco's body to the body of other dancers. As it can be seen in the $D S / D M$ documentary, that transmission is based on exemplification and reproduction. ${ }^{3}$ The dancers watch Greco dancing, listen to his oral instructions and then try to dance in accordance with the same movement principles. To say that a movement principle is reproduced from body to body is not the same as saying that one body mimics another. Rather than formal outcomes, what is transmitted across bodies in this circumstance is a principle of individuation. In dance, movement principles are principles of individuation, for they correspond to a mediation between orders of movement, which enables specific regimes of expression.

1 This project was followed by the Inside Movement Knowledge (IMK) project, which occurred between 2008 and 2010. For a detailed account of both projects' history, see www.insidemovementknowledge.net.

2 I had the chance to meet part of the NRP's team at the first Annual Arts and Sciences Laboratory of the Transmedia Knowledge Base for Performing Arts Project (TKB), which took place at the choreographic centre "O Espaço do Tempo" in Montemor-o-Novo, Portugal, between May 22nd and 28th 2010. For more on the TKB project, see http://tkb.fcsh.unl.pt/. By then the NRP had already finished, but its outcomes were still being developed in the frame of the IMK project. Since this Laboratory was dedicated to "new models of documentation for contemporary dance", the NRP/IMK's team had the opportunity to set up the interactive installation DS/DM there and present their remaining work. This was the only time I accessed the interactive installation's actual set-up and experienced its workings.

3 The DS/DM documentary can be watched at https://vimeo.com/38974588, or found enclosed in the publication (Capturing Intention): Documentation, Analysis and Notation Research Based on the Work of Emio Greco/PC (deLahunta, 2007a). 
The notion of individuation proposed here comes from the work of Gilbert Simondon - the French philosopher who has engaged in reactivating the philosophy of individuation in the 1950 and 1960s, in order to deal with contemporary issues such as the rise of machines and the relationship between culture and nature. For Simondon, "the sole principle by which [individuation] is guided is that of the conservation of being through becoming" (1992: 301), which amounts to saying that individuation is the process by which the potentials of a system are conserved. From an ontogenetic perspective, the principle of individuation corresponds to the operation that enables "the system of energy that is individuating" to realize, in the individual, the "internal resonance of the matter taking form and a mediation between orders of magnitude" (idem, 1964: 44). ${ }^{4}$ From the outset, an individuating system keeps potentials of different orders of magnitude communicating with each other, from which a force strong enough to dephase the system and individuate a determinate state of affairs can emerge. Such force is the potential of disparity. From phase to phase, which is to say from individual to individual, the system restructures the distribution of its energetic potentials, only to keep itself in a state of becoming. As Simondon writes, "the true principle of individuation is mediation, which generally presumes the existence of the original duality of the orders of magnitude and the initial absence of interactive communication between them, followed by a subsequent communication between orders of magnitude and stabilization" (idem, 1992: 304). The system's becoming is therefore tantamount to its own internal resonance. As long as potentials belonging to different orders of magnitude keep affecting one another, the system can individuate adequate resolutions to its self-incompatibility. The principle of individuation is a principle of resonance. ${ }^{5}$

To transfer movement principles across bodies is therefore a transductive process, an operation that can be understood according to the following definition by Simondon: vocabulary/.

5 For more on the notion of individuation, see Gilbert Simondon, L'individuation à la lumière des notions de forme et d'information (Simondon, 2005). 
[Transduction] denotes a process [...] in which an activity gradually sets itself in motion, propagating within a given domain, by basing this propagation on a structuration carried out in different zones of the domain: each region of the constituted structure serves as a constituting principle for the following one, so much so that a modification progressively extends itself at the same time as this structuring operation. [...] The transductive operation is an individuation in progress; it can physically occur most simply in the form of progressive iteration. However, in more complex domains, such as the domains of vital metastability or psychic problematics, it can move forward with a constantly variable step, and expand in a heterogeneous field. (Simondon, 1995: 30-31)

In regard to knowledge, transduction corresponds to the formation of correlated subjects and objects, a process by which the individuation of the known object acts as a functional and structural source for the individuation of the knowing subject. By transferring principles of individuation from body to body, transduction facilitates the operational analogy of knowledge and distributes the resources from where the axiomatic emerges. In fact, it is only because a system individuates through a progressive structuration of potentials, that knowledge can receive from the individuation at stake the principles required for its own constitution. This is the reason why transductive knowledge "can be used as the foundation [...] of analogical paradigms so as to enable us to pass from physical individuation to [...] psychic individuation, and from psychic individuation to the subjective and objective level of the transindividual" (idem).

The movement principles of Greco's characteristic dancing are known to comprise a strong component of internal movement, i.e of bodily movements that occur at orders of magnitude unperceivable to other bodies. Hence the name of the publication: Capturing Intention. In this case, intention regards the intensive qualities of bodily movement and the problematic potentials they create to the individuation of extensive expressions. 
If it can be argued that it is an impossible task to express continuity as such by means of film, software or text, it can also be argued that each of the CI's objects attests the systematic tentative of dealing with this very problem: the fundamental and apparently insurmountable difference between qualitative and quantitative multiplicities. In this sense, each of these objects can be said to express, if not a solution, at least an approximation to the problem itself.

To transfer principles of intensive movement either across bodies or from the dancing body to each of the CI's different domains is equivalent to transducing choreographic problems. On the one hand, this means that the body is intensively problematic and therefore capable of transducing the principles according to which it moves. ${ }^{7}$ On the other, it means that the extensive expression of such intensive problems necessarily implies problems that are of the extensive domain itself. When these domains do not coincide with one another (e.g. the transduction of movement principles from the dancing body to the digital domain), the heterogeneous multiplicity is not only doubled with a difference; it is also submitted to conditions of individuation that require different modes of experimentation. In this sense, EG|PC's knowledge of the DS/ $D M$ 's movement principles is way easier to be transferred to other dancing bodies than to the target domains used to express the CI's objects. Expressing movement principles in those target domains requires specific modes of experimentation and the resolution of problems that are definitely foreign to the knowledge that comes with the experience of dancing. It should nonetheless be noticed that of the four CI's objects mentioned above, only the DVD and the Interactive Installation were in fact created with the intent to be autonomous transducers of the DS/ $D M$ 's movement principles. This is to say that, even if all the CI's objects resulted primarily from the knowledge that EG|PC had of the DS/DM workshop, only these two have individuated from the resolution of problems posed by the encounter between given ideas of dance and the domains targeted to express these ideas. With such resolution, these objects acquired a truly choreographic character. They have become choreographic propositions with which it is possible to learn how to dance according to the DS/DM's movement principles, similarly to what happens in a workshop delivered by EG|PC themselves. These two 
objects are capable of transducing the DS/DM's movement principles into other dancing bodies, facilitating the individuation of a renovated knowledge regarding the intended dancing. Together with the workshop itself, these two choreographic objects emphasize the expressive variability that one same system of choreographic individuation is capable of.

It is worth following the NRP's development and the fact that its first outcome was the video documentary of the workshop, filmed and directed by Maite Bermúdez in 2005. The structure of the documentary follows the structure of the workshop, as it was delivered at ImPulsTanz Festival, in August that year. The workshop is shown as divided in five main parts, designated respectively according to their succession as: 1) "Breathing"; 2) “Jumping"; 3) "Expanding"; 4) "Reducing"; 5) “Transfer". Whereas the first four parts correspond to different principles of movement (or, in other words, movement qualities), the last part is depicted as structured by a dance phrase that is to be filled with (or fuelled by) them. The fact that the successive parts are designated by those terms shouldn't be understood in any general way. Their names are not meant to correspond to the common understanding they might pertain to in any other particular context. Rather, they are meant to specifically depict the problematic structure of the $D S / D M$ 's movement qualities. The fact that there is a tension between the limits of a signifier and the unbounded openness of the signified multiplicity is remarked by Scott deLahunta (one of NRP's specialists in dance and technology) as having been one of the difficulties faced by EG|PC when naming and describing the structure of the workshop:

This difficulty of finding the right words and explanations was, in part, due to the dialectical tension between [the artists] that is inherently a feature of their artistic work [...]. To "decide" what and how to name or explain these parts of $D S / D M$, was to allow it to become fixed, to make it concrete in terminology. However, as mentioned, the result of this difficult work served the needs of the making of the documentary. It also produced the hierarchy of sections and subsections so that the DVD and Installation versions of DS/DM could be created. (deLahunta, 2007a: 21) 
This is to say that the tension between the signified (the variable experiences and expressions of dance) and their signifiers (the words used to name the movement qualities at stake in the workshop) was sufficiently problematic to foster the technical individuation of these two choreographic objects. After all, despite their possible reduction to the limited expression of phonetic or graphic signifiers, monemes are but multiplicities of heterogeneous elements.

With no regard to the structures that followed from naming movement principles in this way, the $D S / D M$ workshop always had a linguistic dimension. As dancer Bertha Bermúdez explains, "passing these dances onto others is [normally] done through instructions with the body and words. [As such] the body has to be clear and the words have to be right" (deLahunta, 2007a: 6). The specification provided by names fulfils this very requirement. If both the DVD and the Interactive Installation are to be capable of transmitting the $D S / D M$ 's movement principles, their expressions have to be structured in a precise and determinate manner. It could nonetheless be argued that instead of names, the different parts of the workshop could have been given numbers, for example. But in contrast to numbers, what the artists' endeavour to find the right words for each of the workshop's movement qualities indicates is the existing connection between the somatic experience of the moving body and the ways in which language and conceptual knowledge are structured in and by the body. The oral explanation of dance is directly related to the conceptual structures according to which the DS/DM's movement principles are organized. It allows for understanding both the knowledge that the artists have of what they do and how it is structured.

The fact that both the NRP and the IMK have turned towards cognitive linguistics to think and analyse the conceptual structures implicated in the DS/DM's movement qualities clearly shows not only the projects' concern with the underlying principles of dancing, but also the acknowledgement that they can be known both somatically and conceptually. According to Bermúdez and cognitive linguist Carla Fernandes, two of the researchers involved in the projects, the interest was in: 
[...] searching for the implicit knowledge that is embedded in choreographic processes and the possible ways of presenting or expressing it. In practice this means [to] start from the premise that the translation and transmission of the imagetic thought of a contemporary choreographer into an embodied-type of thought, via the dancers' bodies, is above all metaphoric (cf. Johnson, 1987 on image schemata in the human brain as being prior to awareness). (Fernandes/Bermúdez, 2010: 29)

This metaphorical character of choreographic transductions can be understood both regarding the dancing body's orientation in relation to the charged ground of its perceptive-affective milieu (i.e. imagetic thought being structured in accordance with this orientation) and regarding the influence that knowledge has on dancing (i.e. extensive movement being determined by the structures of thought). It concerns both the transfer of physical resolutions to the resolution of thought and the transfer of conceptual resolutions to the resolution of dance. After all, "the essence of metaphor is understanding and experiencing one kind of thing in terms of another" (Lakoff/Johnson, 1980: 5). But these are not symmetrical processes. The process by means of which the resolutions of thought follow from the body's physical orientation is not the same as the one whereby conceptual structures affect the actual organization of dance. On the basis of this asymmetry is the assumption that knowledge is characteristically imagetic. It structures images (or it imagines structures) that are neither the body's actual orientation in its milieu, nor any of its other possible expressions. In other words, there is an abstract level of experience that has its own processual autonomy and that allows for the complexification of knowledge to a point where the concepts of understanding can move the body in its extensions with ever more complexity. This corresponds to the idea proposed by cognitive linguist Mark Johnson that the perceptual patterns arising from bodily experience correspond to primary structures that nonetheless organize our abstractions. Such structures, which Johnson calls "image schemata", serve as a basis for the more complex operations of associative thinking, which allow for the formation of structured meanings, concepts and reasonings.

The VERTICALITY schema, for instance, emerges from our tendency to employ an UP-DOWN orientation in picking out meaningful structures of our experience. We grasp this structure of verticality repeatedly in 
thousands of perceptions and activities we experience every day, such as perceiving a tree, our felt sense of standing upright, the activity of climbing stairs, forming a mental image of a flagpole, measuring our children's heights, and experiencing the level of water rising in the bathtub. The VERTICALITY schema is the abstract structure of these VERTICALITY experiences, images, and perceptions. (Johnson, 1987: XV)

From an order recurrently perceived in the physical relations between body and milieu arises an abstraction that, because it bears a particular structure, has its own autonomy and can be related to different situations as experience unfolds. Importantly, the autonomy of such abstractions in relation to the concrete experiences from which they emerge allows for the association between image schemata and for the formation of more complex levels of abstraction and cognition. Such associations between abstractions do not occur without movements of thought, which Johnson considers primarily in metaphorical terms. For the author, metaphors correspond to the way in which image schemata are used to structure a domain of experience different from the one where they have first emerged. The relation between patterns of physical experience and the abstract patterns of thought is therefore a relation of dependency, whereby the image schemata of the latter serve to structure the former. Johnson calls this passage from concrete experience to abstract thinking "metaphorical projection", since it is an operation that can also occur between different levels of abstraction. So conceived, metaphors underlie the ordering of cognition to such a point that considering them only linguistically falls short of their importance. ${ }^{8}$ From the acknowledgement of this importance, it can only follow that the physical experience of a body moving through a milieu of charged and problematic potentials is the very foundation of thought. In Johnson's words:

Understanding via metaphorical projection from the concrete to the abstract makes use of physical experience in two ways. First, our bodily movements and interactions in various physical domains of experience reasoning; 3) The possibility for understanding novel extensions in terms of the conventional correspondences" (Lakoff, 2006: 191). From these characteristics follows that metaphors organize the experience of the world in specific ways and that they can be expressed by means other than speech. 
are structured (as we saw with image schemata), and that structure can be projected by metaphor onto abstract domains. Second, metaphorical understanding is not merely a matter of arbitrary fanciful projection from anything to anything with no constraints. Concrete bodily experience not only constrains the "input" to the metaphorical projections but also the nature of the projections themselves, that is, the kinds of mappings that can occur across domains. (Johnson, 1987: xv)

From this standpoint, it is possible to understand how both dance and speech are capable of providing access to the underlying conceptual structures and implicit instances of knowledge. Since the focus here is the dancing body, both modes of expression can be said to correspond to resolutions that not only implicate movement principles but also the thoughts that arise with them. Insofar as knowledge in general can be addressed on the basis of image schemata, and therefore as being grounded on bodily experiences, both knowing how to dance and knowing how to verbalize this experience necessarily correspond to the same conceptual structure. It is therefore possible to not only address this relation between expressions and abstractions on the basis of the mappings that occur across domains, but also to use those mappings to further express choreo-knowledge. This is precisely what both the DVD and the Interactive Installation do.

By determining ideas of dance in the form of concepts, here synthesized by words, and by using their structures to individuate digital expressions, the concretization of the objects in case has extended the knowledge of the $D S / D M$ workshop into domains that, because they are problematic on their own, have allowed for novel resolutions and renovated perspectives on the workshop. As Pieter Scholten remarks, the knowledge of the workshop didn't change "but it has gotten more layers through this research project" (deLahunta, 2007b: 21). Such layers correspond both to a glossary (which beyond the names already mentioned was fabricated with the intent of discontinuing movement qualities into a greater degree of resolution) and to the multimodal contents created to provide different perspectives on the $D S / D M$, as structured by the glossary. "The $D S / D M$ 's glossary has been the first attempt by EG|PC to 
break down the creative process through the use of words. Such a process provided the different disciplines involved within the research project with a common basis of understanding around the DS/DM workshop" (Fernandes/Bermudez, 2010: 31 ). ${ }^{9}$ It also allowed to depict the conceptual structure of the workshop to a point that was new even to the artists. As much as the DS/DM's glossary comprises a list of interrelated terms - a signifying double of the heterogeneous multiplicity that it represents -, and each of these terms implicates a concept, the glossary can be said to represent the conceptual structure of the workshop. A fact reiterated by the very process of its individuation, as described hereunder:

Definitions and descriptions were constructed through interviews and different transcriptions of the live transmission of the workshop, in some cases complemented by visual demonstrations. Divided in two parts, Inside and Outside, the glossary tried to present the language used by the company (Inside section) versus a more general definition of the same terms gathered from dictionaries (Outside section). (ibidem)

It is beyond the scope of this essay to consider the specificities of the lexicon used in the DS/DM's glossary, yet it matters to acknowledge that all its terms refer to resolutions of the dancing body. The glossary didn't result from a random depiction of choreographic expressions, but rather from a knowledge that primarily regards the dancing body's capacity to differentiate movement qualities. Rather than being an external factor of determination imposed on the workshop for the expression of resolute forms, the glossary should be understood as a possible expression of the diagram according to which the dancing body develops and undergoes phase-shifts, from one movement quality to the next. It is nonetheless noticeable that in order to create it, much effort was put into defining the terms in relation to the narrow context of the $D S / D M$ workshop, in relation to the broader context of EG|PC's artistic work, and in relation to the even broader context of dance and movement analysis. There are different individuations at stake here: there is the individuation of the DS/DM's movement qualities and there is the individuation of the concepts created by the multidisciplinary team of specialists. Whereas the results of the former correspond to the glossary's structure, the results of the latter 
correspond to its contents. The one condition that these two individuations share is the $D S / D M$ 's dancing body. After all, both take it to be a body capable of moving ideas with the potential to determine conceptual and physical resolutions. By using the glossary for indexing and organizing the different contents of the DS/DM's DVD and the Interactive Installation, it became possible to express digitally not only the workshop's structure but also the diagram of its potentials. Precisely because of this, says Bermúdez, "[t]he structure that is used in the Installation and the DVD contains the core of what $D S / D M$ [i.e. $N R P$ and $I M K]$ has achieved in ten years" (deLahunta, 2007a: 21).

Each of the DS/DM workshop's sections and subsections is expressed in the DVD and in the Interactive Installation with a variety of contents. For example, the section "Breathing" is expressed in the DVD with: 1) a written explanation; 2) an oral explanation, i.e. the video recording of a "talking head"; 3) the dancing body's video recording; 4) a close up of the previous; 5) a Labanotation score; 6) a Benesh notation score; and 7) the "Gesture Follower" software. All these contents express the $D S / D M$ 's choreographic nexus and define it further by being in relation to one another. This is what the interface designs of the DVD and the Interactive Installation allow for: to relate in continuity, i.e. the continuity of the user's experience, the differences between the extensive series. The expressive multimodality of these graphic interfaces not only makes explicit the contents' similarity but also the ways in which they differ. In fact, it is precisely this contrast between the same and the different that offers an insight into the $D S / D M$ 's invariant functions, i.e. into the principles of individuation of the choreographic ideas that these objects simultaneously express and hold in potential.

Importantly, the glossary's structure is the formal condition for the different content relations. Both in the DVD and in the Interactive Installation the matters of content are differentiated from and related to one another by means of indexation. For example, all the contents indexed with "Breathing" are enclosed within the same set, which is determined not only by the index itself but also by the nexus resulting from the relations of the contents. This function of indexation is therefore a function of expression. It constrains the many possible relations between matters of content and determinate ideas. In a sense, this function is the same that is required for a body to dance in accordance with the $D S / D M$ 's movement principles. Only by having in mind the concepts according to which it moves, can the dancing body move accordingly. 
This capacity of the $D S / D M$ to structure different domains can be understood as a force that, when encountering contents with a variable degree of indetermination, mediates the problematic potentials therein towards the expressive resolution of a particular set of movement principles. This is the force of the DS/DM's choreographic ideas. Their determination holds in potential the capacity to constrain matters of content, regardless of the domain of individuation. Yet it should be noticed that matters of content and structures of abstraction are absolutely reciprocal: one does not go without the other. If the $D S / D M$ 's choreographic nexus is to be transduced and expressed, the structure of its abstractions needs to be related with actual matters of content. Only by means of this encounter can choreographic ideas be expressed and constituted as the actual ground for other potential transductions. A relation between abstractions and expressions that the DS/DM's DVD and the Interactive Installation mediate in an exemplary way, for they hold the potential of transducing the workshop's movement principles as much as the artists themselves. Overall, this is a capacity that allows us to think of the DS/ $D M$ as one same choreographic object, independently from the domains in which it is or might be expressed.

\section{REFERENCES}

DELAHUNTA, Scott (2007), "The body has to be clear and the words have to be right", in (Capturing Intention): Documentation, Analysis and Notation Research Based on the Work of Emio Greco/PC, ed. Scott deLahunta, Emio Greco/PC and AHK/Lectoraat, pp. 5-9.

- (2007b), "The moment to question... Double Skin | Double Mind", in (Capturing Intention): Documentation, Analysis and Notation Research Based on the Work of Emio Greco/PC, ed. Scott deLahunta, Emio Greco/PC and AHK/Lectoraat, pp. 58-61.

DELEuze, Gilles (1994), Difference and Repetition, Columbia, Columbia University Press.

FERNANDES, Carla and BERMUDEZ, Bertha (2010), "Inventing the interactive glossary: an approach to documenting contemporary dance", Notation: Special Issue of RTRSRCH Journal, 2 (2), pp. 29-31.

JoHnson, Mark (1987), The Body in the Mind: The Bodily Basis of Meaning, Imagination, and Reason, Chicago, University of Chicago Press.

LAKof F, George and Johnson, Mark (1980), Metaphors We Live By, Chicago, University of Chicago Press. MACKENZIE, Adrian (2002), Transductions: bodies and machines at speed, London/New York, Continuum. SIMONDON, Gilbert (1964), L'individu et sa genèse physico-biologique, Paris, PUF.

- (1992), “The genesis of the individual”, in Incorporations, 6, pp. 296-319.

- (1995), L'individu et sa genèse physico-biologique, Grenoble, Editions Jérôme Millon.

- (2005), L'individuation à la lumière des notions de forme et d'information, Bernin, Éditions Jérôme Millon. 


\section{CARLOS MANUEL OLIVEIRA}

É coreógrafo, performer e investigador colaborador no grupo de investigação «Performance e Cognição» da Universidade Nova de Lisboa. Concluiu o doutoramento em Media Studies no âmbito do Programa UT Austin|Portugal e a licenciatura em Contemporary Dance: Context and Choreography no Inter-University Center for Dance de Berlim. 